\title{
CARACTERÍSTICAS DAS LESÕES MUSCULOESQUELÉTICAS SEGUNDO A PERCEPÇÃO DE ATLETAS DE VÔLEI DE PRAIA PROFISSIONAL
}

\author{
Adriana Pereira da Silva*, José Roberto Andrade do Nascimento Júnior**, Daniel Vicentini de Oliveira*** \\ Autor correspondente: Adriana Pereira da Silva - adrikubana@hotmail.com \\ * Graduação em Educação física pelo Departamento de Educação Física da Faculdade Metropolitana de Maringá (FAMMA). \\ ** Graduação em educação física. Doutorado em Educação Física pela Universidade Estadual de Maringá (UEM). Docente \\ do departamento de Educação física da Universidade Federal do Vale do São Francisco (UNVASF). \\ *** Graduação em Educação Física e Fisioterapia. Mestrado em Promoção da Saúde. Doutorado em Gerontologia pela \\ Faculdade de Ciências Médicas da UNICAMP em andamento. Docente do departamento de Educação Física da Faculdade \\ Metropolitana de Maringá (FAMMA).
}

\begin{abstract}
Resumo
Introdução: As lesões musculoesqueléticas são síndromes de dor crônica que podem ocorrer no vôlei de praia (VP) e pode estar ligada aos exercícios repetitivos, a aplicação de força ou trabalho articular muito exigente. Objetivo: Analisar as características das lesões musculoesqueléticas já sofridas por atletas de VP profissional, segundo a percepção dos mesmos. Material e Método: Foram pesquisados 30 atletas de VP da Associação Maringaense de Vôlei de Praia (AMVP) sendo 15 do sexo masculino e 15 do sexo feminino, com idade aproximada de 17 a 32 anos. Foi aplicado questionário com questões relacionadas as percepções dos atletas a respeito das características das lesões nos treinamentos e nas competições. Resultados: Os resultados apontaram que $40 \%$ dos atletas tiveram alguma lesão durante os treinos, onde $75 \%$ foram lesões do tipo aguda e $25 \%$ crônica. Os locais mais lesionados durante os treinos foram à coluna e o tornozelo, ambos com 33,3\%. Já nas competições $50 \%$ dos atletas se lesionaram, sendo $46,67 \%$ dos casos a lesão acometida nos ombros, seguido os tornozelos com $26,69 \%$. As consequências das lesões como abandono da competição e baixo desempenho foram relatadas por $26,68 \%$ dos atletas. Conclusão: Segundo a percepção dos atletas, verificou-se que a maioria dos atletas de VP já se lesionou durante os treinos e competições, sendo coluna, ombro e tornozelo as regiões mais acometidas, e que isto tem como consequência baixo desempenho e/ou abandono de competições.
\end{abstract}

Palavras-chave: Esporte; Exercício físico; Voleibol; Fisioterapia. 


\title{
CHARACTERISTICS OF MUSCULOSKELETAL INJURIES ACCORDING TO THE PROFESSIONAL BEACH VOLLEYBALL ATHLETES
}

\begin{abstract}
Introduction: Musculoskeletal injuries are chronic pain syndromes that can occur in beach volleyball (VP) and can be linked to repetitive exercises, the application of force or work that is very demanding to the joints. Objective: To analyze the perception of professional beach volleyball (BV) athletes concerning the characteristics of musculoskeletal injuries already suffered. Methods: We searched $30 \mathrm{BV}$ athletes from the Maringaense Association of Beach Volleyball (AMVP), being 15 male and 15 female, from 17 to 32 years old. Questionnaires were applied on the perceptions of athletes about the characteristics of injuries in training and in competitions. Results: The results showed that $40 \%$ of athletes had experienced an injury during training, with $75 \%$ of the injuries being acute and $25 \%$ being chronic. The most injured spots during the training were the spine and ankle, both with $33.3 \%$. During competitions, $50 \%$ of the athletes were injured, with lesions on the shoulders in $46.67 \%$ of the cases and ankles in $26.69 \%$ of the cases. The consequences of those injuries such as quitting the competition and poor performances were reported by $26.68 \%$ of the athletes. Conclusion: It was found that, according to the BV athletes, most professionals have already been injured during training and competitions, being column, shoulder and ankle the regions found to be more affected, and that could result in low performance and/or quitting competitions.
\end{abstract}

Keywords: Sport; Physical exercise; Volleyball; Physiotherapy.

\section{INTRODUÇÃO}

O Vôlei de Praia (VP) possui uma grande variedade de técnicas e táticas bem semelhantes ao vôlei de quadra, porém possui também características, de certa forma, bastante diferentes, pelo fato de cada equipe ser composta por apenas dois jogadores e pela grande influência das condições externas, como por exemplo, as climáticas e das ações exercidas em uma areia seca e macia. Esta modalidade é extremamente dinâmica e, quando realizada para alto rendimento, necessita de um treinamento específico que procura desenvolver uma estrutura muscular sólida e equilibrada com a finalidade de reduzir os possíveis riscos de lesões durante a partida e treinamentos, já que o VP é realizado em uma superfície instável, o que deixa os atletas mais propícios a se lesionarem com mais frequência.(1)
Os diferentes tipos de pressão que um atleta de VP sofre durante a competição e nos treinamentos, podem gerar altos níveis de estresses, transformando-se em fatores negativos e redutores do desempenho. Níveis elevados de estresses, em geral, aumentam a tensão muscular e criam déficits de atenção. Uma tensão muscular excessiva pode reduzir a flexibilidade, a coordenação motora e a eficiência muscular, impedindo que os atletas adaptem rápidos comportamentos e padrões para evitar situações perigosas ou agir de maneira apropriada a um bom rendimento, aumentando o risco de lesões musculoesqueléticas. (2) Associado a isto, a falta de assistência de um profissional qualificado é prejudicial à saúde do atleta de VP, causando lesões, algumas 
graves e, consequentemente, o abandono do esporte. (3)

As lesões musculoesqueléticas podem afetar diferentes partes do corpo, como, por exemplo, o ombro, o cotovelo, a mão e o punho, o joelho, a coluna vertebral e o quadril, são síndromes de dor crônica que ocorrem no exercício de uma atividade esportiva e por isso está ligada aos exercícios repetitivos, a aplicação de força ou trabalho que requeira posição das articulações muito exigentes. Independentemente do tipo de lesão, as mesmas são resultantes de uma complexa interação de fatores intrínsecos, psicológicos e extrínsecos. ${ }^{(4)}$

Na região do ombro, devido ao desalinhamento articular causado pelo desequilíbrio de força entre músculos rotadores externos, mais fracos e pouco trabalhados, e os rotadores internos, fortes e bem trabalhados. No ataque a uma explosão de força dos rotadores internos, os rotadores externos realizam uma contração excêntrica para a desaceleração final do ataque, o que provoca um stress nos tendões do manguito rotador, que com uso repetitivo acaba sendo acometido. ${ }^{(5)}$

As lesões na articulação do joelho estão ligadas diretamente ao salto que é praticamente indispensável dentro do VP, sendo a articulação mais utilizada e mais sobrecarregada durante a partida. ${ }^{(6)} A$ região lombar, mesmo não sendo um local de altas incidências de lesões, pode ser afetada em atletas de VP. Uma boa preparação pré-competição e para a realização dos treinamentos pode evitar a presença de lombalgias. Essa região suporta constantemente exercícios de alto impacto e grande força isométrica. ${ }^{(7)}$

As lesões do tornozelo mais acometidas são o entorse e fratura, mas estas têm um número bastante reduzido. As lesões de ordem muscular como as contraturas e os estiramentos, aparecem como as principais lesões agudas dentro do VP. Perante as considerações apresentadas é possível perceber que a incidência de lesões no VP e tão elevada quanto à de qualquer outro esporte, seja de alto rendimento ou amador. ${ }^{(8)}$
Há uma relação estreita entre a prática esportiva e lesão esportiva, no entanto, há escassez de pesquisas brasileiras sobre lesões esportivas em atletas jovens de VP. A investigação de lesões em jovens jogadores de VP podem facilitar o estabelecimento de uma melhor e consistente estratégia preventiva. As lesões do aparelho locomotor pode afetar ações motoras futuras e até mesmo comprometer a continuidade na carreira de atleta. ${ }^{(9)}$ Assim, há necessidade de investigar as caracterísicas de lesões esportivas de modo a auxiliar na determinação de estratégias específicas em matéria de prevenção de lesões e de manutenção da saúde entre os jogadores de VP.

Por isso o presente estudo visa responder à seguinte questão norteadora: Como se caracterizam as lesões musculoesqueléticas em atletas de VP profissional? O mesmo teve como objetivo analisar as características das lesões musculoesqueléticas já sofridas por atletas de VP profissional, segundo a percepção dos mesmos.

\section{METODOS}

Este estudo caracteriza-se por ser do tipo descritivo, observacional e transversal aprovado pelo Comitê de Ética em Pesquisa do Centro Universitário Cesumar (UNICESUMAR) por meio do parecer $1.173 .053 / 2015$.

A população deste estudo foi composta de atletas de VP do município de Maringá do estado do Paraná. Para seleção da amostra, foram inclusos atletas de ambos os sexos, com pelo menos dois anos de prática profissional nesta modalidade. Foram pesquisados 30 atletas de VP da Associação Maringaense de Vôlei de Praia a (AMVP) sendo 15 do sexo masculino e 15 do sexo feminino, com idade aproximada de 17 a 32 anos.

A caracterização dos atletas foi avaliada segundo a percepção dos mesmos, por meio de questionário semiestruturado, composto por informações referentes à idade, sexo, estado civil, situação ocupacional, renda mensal em salário mínimo de 
referência no Censo Demográfico 2015 do Instituto Brasileiro de Geografia e Estatística. Foi questionado também a respeito da frequência semanal de treino, há quanto tempo participa de competições profissionais, há quanto tempo faz parte da associação.

Para avaliação das características das lesões, foi aplicado um questionário elaborado pelos próprios autores, com questões referentes ao diagnóstico médico, data aproximada do aparecimento da lesão, localização anatômica da lesão, como aconteceu à lesão, mecanismo da lesão como ocorreu, quais os fatores associados à lesão, lesões sofridas no treinamento ou competição, se a lesão afetou o desempenho nos jogos. A coleta de dados foi rea- lizada por meio de entrevista direta antes e depois do dia de treinamento dos atletas, após a autorização do responsável do local de pesquisa.

Para a análise dos dados, foi utilizada a estatística descritiva e os resultados foram representados por meio de frequência e percentual para as variáveis categóricas, e média e desvio-padrão para as variáveis numéricas. Os dados foram analisados no software SPSS versão 20.0.

\section{RESULTADOS}

Os dados referentes ao perfil dos atletas pesquisados encontram-se na tabela 1 .

Tabela 1 - Distribuição de frequência do perfil dos atletas adultos de vôlei de praia do município de Maringá-PR

\begin{tabular}{|c|c|c|}
\hline VARIÁVEIS & $\mathrm{F}$ & $\%$ \\
\hline \multicolumn{3}{|l|}{ Sexo } \\
\hline Masculino & 15 & 50 \\
\hline Feminino & 15 & 50 \\
\hline \multicolumn{3}{|l|}{ Estado civil } \\
\hline Casado & $\mathrm{O} 2$ & 6,7 \\
\hline Não Casado & 28 & 93,3 \\
\hline \multicolumn{3}{|l|}{ Escolaridade } \\
\hline Ensino Médio Incompleto & O9 & 30 \\
\hline Ensino Médio Completo & $\mathrm{O} 4$ & 13,3 \\
\hline Ensino Superior Incompleto & 11 & 36,7 \\
\hline Ensino Superior Completo & O6 & 20 \\
\hline \multicolumn{3}{|l|}{ Renda mensal } \\
\hline Menos de 1 salário mínimo & 16 & 53,4 \\
\hline 1 a 2 salários mínimos & 10 & 33,3 \\
\hline Mais de 2 salários mínimos & $\mathrm{O} 4$ & 13,3 \\
\hline \multicolumn{3}{|c|}{ Participação em competições profissionais } \\
\hline 1 a 5 anos & 21 & 70 \\
\hline Mais de 5 anos & O9 & 30 \\
\hline \multicolumn{3}{|l|}{ Tempo na Associação de Vôlei de praia } \\
\hline 1 a 5 anos & 21 & 70 \\
\hline Mais de 5 anos & O9 & 30 \\
\hline \multicolumn{3}{|l|}{ Treinos por semana } \\
\hline 1 a 3 treinos & $\mathrm{OO}$ & O \\
\hline 4 ou mais treinos & 30 & 100 \\
\hline
\end{tabular}


Os atletas apresentaram uma média de idade de $20,23 \pm 3,95$ anos, sendo que foram avaliados 15 atletas do sexo masculino ( $20 \pm 3,33$ anos) e 15 do sexo feminino $(20,4 \pm 4,61$ anos $)$.

Nota-se (Tabela 1) a prevalência de atletas não casados (93,3\%) com renda mensal de menos de um salário mínimo $(53,4)$ com ensino médio incompleto $(30,0)$ e superior incompleto $(36,7 \%)$. Observou-se também que a maioria dos atletas participa de competições profissionais e faz parte da associação maringaense de VP entre um e cinco anos $(70 \%)$ e todos os atletas treinam quatro ou mais vezes por semana (100\%).

Verificou-se (Tabela 2) que apenas 12 atletas $(40 \%)$ se lesionaram durante treinamentos. Destes 12 atletas, $66,7 \%$ (08) sofreram apenas uma lesão durante treinamentos, $75 \%$ tiveram lesão aguda.

Tabela 2 - Distribuição de frequência dos dados relativos às lesões musculoesqueléticas durante treinamentos dos atletas adultos de vôlei de praia da cidade de Maringá-PR

\begin{tabular}{lll}
\hline \multicolumn{1}{c}{ VARIÁVEIS } & $F$ & $\%$ \\
\hline Se lesionou durante treinos & 12 & 40 \\
Sim & 18 & 60 \\
Não & & \\
Frequência de lesões (n=12) & 08 & 66,7 \\
$\quad$ Uma & 04 & 33,3 \\
Duas ou mais & & \\
Tipo de lesão (n=12) & 09 & 75 \\
Aguda & 03 & 25 \\
Crônica & & \\
Última lesão (n=12) & 05 & 41,7 \\
Menos de 1 ano & 07 & 58,3 \\
1 a 5 anos & & \\
Localização anatômica (n=12) & 02 & 16,7 \\
Ombro & 04 & 33,3 \\
Coluna & 02 & 16,7 \\
Joelho & 04 & 33,3 \\
Tornozelo & & \\
Diagnóstico (n=12) & 04 & 33,3 \\
Entorse & 02 & 16,7 \\
Luxação & 01 & 8,3 \\
Fratura & 01 & 8,30 \\
Distensão muscular & 02 & 16,7 \\
Lesão ligamentar & 02 & \\
Hérnia de disco & & \\
\hline
\end{tabular}

A maioria das lesões ocorreu na coluna (33,3\%) e tornozelo $(33,3 \%)$, com diagnóstico de entorse $(33,3 \%)$, luxação $(16,7 \%)$ lesão ligamentar $(16,7 \%)$ e hérnia de disco $(16,7 \%)$. Em relação ao período da última lesão, verificou-se que $58,3 \%$ dos atletas se lesionaram nos últimos cinco anos, enquanto $41,7 \%$ se lesionaram há menos de um ano.

Observou-se (Tabela 3) que as lesões nos treinamentos causaram na maioria das vezes a retirada do atleta do mesmo $(41,7 \%)$ ou a continuida- 
de no treinamento, mas com queda no desempenho $(41,7 \%)$ sendo que os principais fatores relatados pe- los atletas foram o aquecimento insuficiente $(58,4 \%)$ e outros fatores do contexto esportivo (25\%).

Tabela 3 - Distribuição de frequência dos dados relativos às consequências causadas no desempenho e aos fatores associa dos pelas lesões musculoesqueléticas em treinamentos dos atletas de vôlei de praia de Maringá-PR

\begin{tabular}{lcc}
\hline \multicolumn{1}{c}{ VARIÁVEIS } & $\mathrm{F}$ & \% \\
\hline Consequência no desempenho (n=12) & & \\
Exclusão do treino & 05 & 41,7 \\
Exclusão do treino, mas retorno ainda durante o treino & 01 & 8,3 \\
Continuou treinando, mas com queda no desempenho & 05 & 41,7 \\
Não influenciou no desempenho & 01 & 8,3 \\
Fatores associados (n=12) & & \\
Falta de segurança & 01 & 8,3 \\
Aquecimento insuficiente & 07 & 58,4 \\
Má técnica & 01 & 8,3 \\
Outros & 03 & 25 \\
\hline
\end{tabular}

Verificou-se (Tabela 4) que metade dos atletas (15) já se lesionou durante competições, sendo que a maioria sofreu apenas uma lesão $(86,6 \%)$, do tipo aguda $(86,7 \%)$, com localização anatômica no ombro $(46,7 \%)$ e tornozelo $(26,7 \%)$ e diagnóstico de entorse $(33,3 \%)$ ou distensão muscular $(33,3 \%)$.

Tabela 4 - Distribuição de frequência dos dados relativos às lesões musculoesqueléticas ocorridas durante competições dos atletas adultos de vôlei de praia da cidade de Maringá-PR

(continua)

\begin{tabular}{lcc}
\hline \multicolumn{1}{c}{ VARIÁVEIS } & $F$ & $\%$ \\
\hline Se lesionou durante competições & 15 & 50 \\
Sim & 15 & 50 \\
Não & & \\
Frequência de lesões (n=15) & 13 & 86,6 \\
Uma & 01 & 6,7 \\
Duas & 01 & 6,7 \\
Três ou mais & & \\
Tipo de lesão (n=15) & 13 & 86,7 \\
Aguda & 02 & 13,3 \\
Crônica & & \\
Última lesão (n=15) & 07 & 46,6 \\
Menos de 1 ano & 08 & 53,4 \\
1 a 5 anos & & \\
Localização anatômica (n=15) & 07 & 46,7 \\
Ombro & 02 & 13,3 \\
Punho & 02 & 13,3 \\
Joelho & 04 & 26,7 \\
Tornozelo &
\end{tabular}


Tabela 4 - Distribuição de frequência dos dados relativos às lesões musculoesqueléticas ocorridas durante competições dos atletas adultos de vôlei de praia da cidade de Maringá-PR

(conclusão)

\begin{tabular}{|c|c|c|}
\hline VARIÁVEIS & $\mathrm{F}$ & $\%$ \\
\hline \multicolumn{3}{|l|}{ Diagnóstico $(n=15)$} \\
\hline Entorse & 05 & 33,3 \\
\hline Distensão muscular & 05 & 33,3 \\
\hline Luxação & $\mathrm{O} 2$ & 13,3 \\
\hline Fratura & 01 & 6,67 \\
\hline Tendinite & 01 & 6,67 \\
\hline Lesão ligamentar & 01 & 6,67 \\
\hline
\end{tabular}

Verificou-se (Tabela 5) que as lesões possibilitaram a continuidade na competição, mas com queda no desempenho (60\%). Os principais fatores relatados pelos atletas na queda do desempenho foram o aquecimento insuficiente $(33,3 \%)$ outros fatores do contexto esportivo $(26,7 \%)$.

Tabela 5 - Distribuição de frequência dos dados relativos às consequências causadas no desempenho e aos fatores associados pelas lesões musculoesqueléticas em competições dos atletas de vôlei de praia de Maringá-PR

\begin{tabular}{lcc}
\multicolumn{1}{c}{ VARIÁVEIS } & $\mathrm{F}$ & $\%$ \\
\hline Consequência no desempenho (n=15) & & \\
Exclusão da competição & 04 & 26,7 \\
Exclusão do evento, mas retorno ainda durante os jogos & 02 & 13,3 \\
Continuou competindo, mas com queda no desempenho & 09 & 60 \\
Fatores associados (n=15) & & \\
Falta de segurança & 01 & 6,7 \\
Condições do piso & 03 & 20 \\
Tempo entre aquecimento e competição & 01 & 6,7 \\
Aquecimento insuficiente & 05 & 33,3 \\
Má técnica & 01 & 6,7 \\
Outros & 04 & 26,7 \\
\hline
\end{tabular}

\section{DISCUSSÃO}

O objetivo deste estudo foi o de analisar as características das lesões musculoesqueléticas já sofridas por atletas de VP profissional, segundo a percepção dos mesmos.

A maioria dos atletas participa de competições profissionais e faz parte da associação maringaense de VP entre um e cinco anos, no qual esta asso- ciação foi fundada em 2001, e treinam quatro ou mais vezes por semana. Segundo Ribeiro ${ }^{(8)}$ e Barbanti, ${ }^{(10)}$ o treinamento é de fundamental importância para que o atleta possa realizar os seus objetivos de uma maneira completa, onde consiste em elaborações de táticas (pensar e agir) nas técnicas dos movimentos a serem realizados, exercitar as capacidades motoras e os fundamentos que são exigidas no VP, bem como também trabalhar o psicossocial dos atletas nas competições e para 
que os resultados sejam satisfatórios são necessários treinos mais focados e com maiores frequências semanais.

Porém, segundo Zatsiorsky, ${ }^{(11)}$ o treinamento excessivo em busca de maior desempenho e títulos, pode ter consequências como as lesões agudas que o correm durante o treino, no momento em si, e as crônicas que são as lesões que já se prolongam por mais tempo, em que muitas vezes não foram tratadas corretamente podendo ocasionar outras lesões. Verificou-se que apenas $40 \%$ do presente estudo se lesionaram durante treinamentos.

Esse fator pode ter características intrínsecas (idade, sexo, desenvolvimento motor) e características extrínsecas (cargas dos treinos, solo, clima).

Yiannis $^{(12)}$ mostrou em seu estudo diferenças significativas na forma como o jogo foi jogado de acordo com o sexo dos jogadores, ou seja, o uso mais freqüente de salto e poder de ataque no jogo do sexo masculino. $O$ autor observou desigualdades no potência muscular dos jogadores, como um dos principais fatores para o tipo de jogo disputado. O equilíbrio da potência muscular se torna imprescindível para prevenção de lesões. ${ }^{(13)}$

Notou-se em um estudo realizado por Menezes, Menezes e Santos ${ }^{(14)}$ com 32 atletas profissionais de VP masculino, que $68,75 \%$ dos atletas foram lesionados, onde $81,8 \%$ tiveram lesão crônica e $18,2 \%$ lesões agudas.

Como salientado, a maioria das lesões ocorreu na coluna (hérnia de disco) e tornozelo (entorse, luxação, lesão ligamentar). Um estudo com 32 atletas de VP do sexo masculino, ${ }^{(11)}$ obteve maiores índices de lesões nos joelhos (oito lesões), lombar e ombros (seis lesões), sendo os joelhos a articulação mais sobrecarregada no VP. Ghitotocc e Gonçalves ${ }^{(15)}$ verificaram em seu estudo bibliográfico que os tornozelos, joelhos, coluna, entorse e hérnia de disco são as lesões que mais acarretaram em lesões no VP.

A hérnia de disco pode ser proveniente de grandes cargas depositadas na coluna vertebral durante os treinamentos e competições e, quanto a isso, segundo Picollo, (1) o ambiente onde o atleta treina influência muito nessa e em outras lesões. O VP é realizado em um ambiente instável como o clima e a areia, e por isso que um grande número de lesões ocorre na coluna, região que suporta carga, e tornozelos, que promovem estabilidade.

Quanto ao treinamento, não deve focar somente nas técnicas e táticas dos atletas, mas também em grupos musculares específicos para que eles possam ser melhores trabalhados e evitar sobrecarga e lesões por falta de exercícios complementares.

Segundo Marques Junior ${ }^{(6)}$ o grande número de lesões no VP pode ser decorrente das condições na elaboração dos treinamentos, onde as cargas são focadas somente em um desempenho. $O$ treinamento precisa também focar no aquecimento e alongamento, pois a flexibilidade também é importante para o desempenho do atleta.

A incidência de lesões em atletas pode estar relacionada a idade, sexo, condição física, desenvolvimento motor, dieta e fatores psicológicos, bem como que estão associadas com os requisitos específicos de cada modalidade, o tipo de equipamentos utilizados, organização e formação de carga, a concorrência, condições meteorológicas ou uma combinação de fatores. (3) Outros fatores podem ser citados, como a experiência do atleta na prática do esporte, o número de horas por semana de treinamento, dentre outros.

Para a recuperação das lesões são necessárias diversas atuações, como uma equipe multidisciplinar, onde o repouso é indispensável para a recuperação. Assim, o retorno desse atleta aos treinos pode ter como consequência o desempenho inferior comparado ao desempenho antes da lesão, ou também pelo fato do atleta ainda sentir algumas dores. Muitas vezes, o atleta precisa ser afastado dos treinamentos por diversos motivos, como a recuperação total dos membros traumatizados ou porque a lesão não possibilita mais o retorno do atleta as suas realizações esportivas intensas ou também outros fatores como as causas psicológicas. ${ }^{(14)}$ Outros exercícios como a flexibilidade e a força precisão ser trabalhadas para a prevenção 
de lesões e afastamento dos atletas nos treinos e campeonatos. ${ }^{(6)}$

Nas competições, verificou-se que metade dos atletas já se lesionou, sendo a região do ombro a mais acometida, segundo a percepção dos atletas. O ombro é sede frequente de lesões nos esportes competitivos. Na literatura a incidência varia de 8 a $13 \%$ de todas as lesões atléticas. As lesões nos esportes de arremesso, como no VP, são comuns na prática clínica. As lesões nos membros superiores giram em torno de $75 \%$ do total e a articulação do ombro é a região mais afetada. ${ }^{(15)}$

Estudo de Gomes, Medeiros, Lira, Cordeiro, Silva e Sant'Ana ${ }^{(16)}$ com 102 atletas de VP, onde 50 são do sexo masculino e 52 do sexo feminino, sendo competidores do $6^{\circ}$ campeonato mundial universitário em Maceió em 2012, desses, 33,5\% teve os joelhos como localização anatômica da lesão, (onde 42,8\% eram do sexo masculino e $20,0 \%$ feminino), seguido dos ombros com $16,7 \%$, cabeça, lombar, quadril, coxa, perna, tornozelo e pés, todos com $8,3 \%$.

O VP é uma modalidade esportiva que tem muitos impactos, como o dos membros superiores na bola, dos membros inferiores com o solo como também, muitas vezes o atleta se lança ao chão para pegar a bola. Esses impactos influenciam nas lesões como o ombro, a distensão muscular, tornozelo e as entorses. Portanto, treinamentos diversificados também são necessários para que os atletas trabalhem grupos musculares específicos para a prevenção de lesões nos membros que mais as ocorre. ${ }^{\left({ }^{(6)}\right.}$

Geralmente, após o acometimento da lesão, o atleta opta por ficar na competição, seja pela baixa gravidade lesão, seja pelo fato de não pode realizar substituição. No entanto, a lesão pode ser agravada durante a competição. Assim, é de grande valia que a equipe como um todo reavalie as condições físicas e psicológicas dos atletas, para que a sua saúde não tenha danos mais graves e a recuperação seja total.

À volta à calma, como alongamentos, relaxamentos são imprescindíveis ao atleta depois de treinos e/ou campeonatos, assim, resíduos de creatinase e ácido lático sejam eliminados e prevenindo futuras lesões. A supervisão de profissionais da saúde como os professores de educação física e fisioterapeutas são muito importantes para acompanharem os treinamentos evitando lesões a auxiliando nos movimentos correto. ${ }^{(17)}$

Os alongamentos e os aquecimentos são necessários para evitar as lesões, no entanto, muitos atletas relataram que tiveram queda no desempenho por aquecimento insuficiente. Entende-se por aquecimento todas as medidas que servem como preparação para a atividade, seja para o treinamento ou para competição, cuja intenção é a obtenção do estado ideal físico e psíquico bem como preparação cinética e coordenativa na prevenção de lesões. Já o alongamento é uma manobra terapêutica utilizada para aumentar a mobilidade dos tecidos moles por promover aumento do comprimento das estruturas que tiveram encurtamento adaptativo, podendo ser definido também como técnica utilizada para aumentar a extensibilidade musculotendínea e do tecido conjuntivo periarticular, contribuindo para aumentar a flexibilidade articular, isto é, aumentar a Amplitude de Movimento (ADM) e também evitar lesões musculoesqueléticas. ${ }^{(18)}$

O estudo apresenta algumas limitações como o tamanho pequeno da amostra, por se tratar de atletas de uma única associação de VP do município, e por utilizar a percepção dos mesmos como forma de coleta dos dados, fato este que implica em respostas subjetivas a respeito das características das lesões musculoesqueléticas. Entretanto, mesmo com as limitações apontadas, esta pesquisa poderá fornecer aos profissionais da saúde importantes conhecimentos sobre a percepção dos atletas a respeito de suas próprias lesões, além a importância de se prevenir as lesões musculoesqueléticas, principalmente no que se refere a qualidade dos treinamentos.

Diante dos resultados obtidos, sugere-se que novas pesquisas sejam realizadas com atletas de VP, assim como estudos mais aprofundados sobre as reais causas das lesões nestes atletas. 


\section{CONCLUSÃO}

Segundo a percepção dos atletas de VP, verificou-se que a maioria deles já se lesionou durante os treinos e competições, sendo coluna, ombro e tornozelo as regiões mais acometidas, e que isto tem como consequência o baixo desempenho e/ou abandono de competições.

\section{REFERÊNCIAS}

1. Nista-Piccolo VL. Pedagogia dos esportes. $3^{a}$ ed. São Paulo: Papirus; 1999.

2. Stefanello J. Situações de estresse no vôlei de praia de alto rendimento: um estudo de caso com uma dupla olímpica. Rev Port Cien Desp. 2007;7(2):232-244.

3. Quemelo PRV, Coelho AR, Bachur JÁ, Morrayne MA, Zaia JE, Gadotti I. Prevalence of sports injuries during the 53th Regional Games in Franca (SP), Brazil. Fisioter. pesqui. 2012;19(3):256-260.

4. Walker B. Lesões no esporte: Uma abordagem anatômica. São Paulo: Manole; 2010.

5. Ferreira AP. Da iniciação ao alto nível: um percurso para repensar. Treino Desportivo. $3^{a}$ ed. São Paulo, 2003. p. 28-33.

6. Marques Junior NK. Principais lesões no atleta de voleibol. Lecturas, Educación Física y Deportes. 2004;10(68).

7. Lopes PM, Mackert TC, Yau MCH, Facci LG. Isostreching no tratamento da lombalgia crônica. Fisioter. bras. 2006;7(2):99-103.

8. Ribeiro F. Incidência de lesões no voleibol: Acompanhamento de uma Época Desportiva. Arq. fisioter. 2007;1(3):29-34.

9. Vanderlei FM, Bastos FN, Tsutsumi GYC, Vanderlei LCM, Netto Júnior J, Pastre CM. Characteristics and contributing factors related to sports injuries in young volleyball players. BMC res. notes. 2013;6(415):1-7.

10. Barbanti VJ. Teoria e prática do treinamento esportivo. $2^{\mathrm{a}}$ ed. São Paulo: Blucher; 1997.

11. Zatsiorsky VM. Biomecânica no esporte: Performance do desempenho e prevenção de lesões. Rio de janeiro: Guanabara Koogan; 2013.

12. Yiannis L. Comparison of the basic characteristics of men's and women's beach volley from the Athens 2004 Olympics. International Journal of Performance Analysis in Sport. 2008;8:130-137.

13. Ferreira AP, Gomes AS, Ferreira CES, Arruda M, França NM. Avaliação do desempenho isocinético da musculatura extensora e flexora do joelho de atletas de futsal em membro dominante e não dominante. Rev. bras. ciênc. esporte. 2010;32(1):229-243.

14. Menezes FS, Menezes RBPC, Santos GM. Análise de lesões mais frequentes nos atletas de voleibol de praia masculino de elite. Lecturas, Educacióm Física y Deportes. 2008;12(116).

15. Ejnisman B, Andreoli CV, Carrera EF, Abdalla RJ, Cohen M. Lesões músculo-esqueléticas no ombro do atleta: mecanismo de lesão, diagnóstico e retorno à prática esportiva. Rev. bras. ortop. 2001;36(1):389-393.

16. Gomes IGA, Medeiros JD, Lira PMA, Cordeiro SML, Silva IN, Sant'Ana HGF. Análise epidemiológica de lesões durante o $6^{\circ}$ campeonato mundial universitário voleibol de praia. Ciências Biológicas e da Saúde. 2014;2(1):151-163.

17. Ghirotocc FMS, Gonçalves A. Lesões desportivas no voleibol. Rev. educ. fis. 1997;8(1):45-49.

18. Alencar TAMD, Matias KFS. Princípios fisiológicos do aquecimento e alongamento muscular na atividade esportiva. Rev. bras. med. esporte. 2010;16(3):230-234. 